\title{
Assessment of nitrate contamination in unsaturated zone of urban areas: The case study of Tehran, Iran
}

\author{
Vahid Joekar-Niasar · Behzad Ataie-Ashtiani
}

Received: 21 January 2008/Accepted: 25 June 2008/Published online: 12 July 2008

(C) The Author(s) 2008

\begin{abstract}
Modeling fate of nitrogen in unsaturated and saturated zone is a complex process, which requires detailed geochemical data. Complexities of the process as well as data insufficiencies are two major issues, which make quantitative assessment of the problem more complicated. In this work, a lumped-parameter model (LPM) is proposed that has been evaluated for a data-limited case to study temporal and steady-state behavior of Nitrate and Ammonium in unsaturated zone. The concentration of components in the model are assumed as the depth-averaged concentrations, and dispersive fluxes have been neglected. The case study area is Tehran City aquifer, which is highly contaminated by domestic wastewater discharge into the groundwater. Three sources for Nitrogen contamination have been studied, namely domestic wastewater, park/recreational applications, and wet deposition. Results show that Nitrate production in the first few meters $(<5 \mathrm{~m})$ is quite large. To compare the model results with the measurements, error estimation analysis based on Vornoi map has been fulfilled. Finally, it is shown that there is a fairly good correlation coefficient between simulation and measurements, which approves the validity of the LPM.
\end{abstract}

Keywords Nitrate - Unsaturated zone ·

Lumped-parameter model · Wastewater · GIS · Tehran

V. Joekar-Niasar ( $\square)$

Environmental Hydrogeology Group, Faculty of Earth Sciences,

Utrecht University, the Netherlands Budapestlaan 4,

Utrecht Postal Code 3584CD, The Netherlands

e-mail: joekar@geo.uu.nl

B. Ataie-Ashtiani

Civil Engineering Department,

Sharif University of Technology,

P.O. Box 11365-9313, Tehran, Iran

\section{Introduction}

In recent decades, water shortage has become a severe problem in arid and semi-arid countries. Because of the importance of groundwater in supplying drinking water, its environmental aspects such as contamination transport in groundwater have been significantly studied. Many researches have focused on contamination of groundwater due to anthropogenic sources mainly by agricultural activates and domestic wastewater. Nitrate contamination of groundwater is one of the main subjects in many of these studies (e.g., Lagerstedt et al. 1994; D' Agostino et al. 1998; DeSimone and Howes 1998; Abu Maila et al. 2004; Schilling and Wolter 2007). According to Tesoriero and Voss (1997), a proper prediction of $\mathrm{NO}_{3}-\mathrm{N}$ leaching in the unsaturated zone is essential for the assessment of groundwater contamination and ultimately for development of a nutrient management protocol. The World Health Organisation (1996) has established maximum permissible limits for Nitrate in water used for drinking purposes at 10 $\mathrm{mg} / \mathrm{L} \mathrm{NO}_{3}-\mathrm{N}$. Ingestion of Nitrate by infants can cause low oxygen level in blood and a potentially fatal condition (Spalding and Exner 1993; Nolan 2001).

To have a reliable tool for quantitative management of pollution problems, researchers have developed several models for different applications. These models can be classified under two large groups; qualitative assessment tools and quantitative assessment tools. To predict Nitrate contamination risks and fates in large areas, different methods such as vulnerability assessment index, mass balance, and lumped-parameter models (LPMs) have been developed. DeSimone and Howes (1998) determined the percentages of different processes of Nitrogen fate such as sorption, nitrification, volatilization, etc., in a large area. Wakida and Lerner (2005) and Groffman et al. (2004) have 
measured total Nitrogen loadings in large-scale urban areas. Ju et al. (2006) has studied the annual Nitrogen budget and groundwater Nitrate concentrations in three major intensive cropping systems in north of China. Nolan (2001) has also investigated relationship among precipitation, population, and Nitrate concentration in groundwater. Joekar-Niasar (2003) and Joekar-Niasar and Ataie-Ashtiani (2003) have suggested an assessment approach based on the modified DRASTIC (Aller et al. 1987) for domestic wastewater source in urban areas. Since large-scale studies of groundwater contamination cover mostly qualitative aspects of problem (Osborn et al. 1998, Rupert 2001), it is necessary to define an approach for quantitative assessment of contamination.

Existing quantitative models are mostly based on soilplant systems. Antonopoulos and Wyseure (1998) developed WANISIM model for modeling fate and transport of Nitrogen in agricultural applications. Hutson and Wagenet (1991) developed LEACHN to simulate transport of Nitrogen in soil using Richard's equation. Kaluarachchi and Parker (1998) developed a three-dimensional finiteelement model for simulation of transport and transformation of Nitrogen in unsaturated zone. There are a large number of accurate numerical methods and models, available for solute transport equation with reaction term (e.g., Ataie-Ashtiani and Hossaini 2005a, b; Ataie-Ashtiani et al. 1999). One of the few models for nonagricultural applications was developed by MacQuarrie et al. (2001). They developed a detailed model for simulating fate and transport of Nitrogen components in a septic tank system in saturated and unsaturated zones. This model also includes detailed geochemical, physical, and biochemical processes. However, involved complexities in these models make their applicability limited to small areas. Although many numerical models have been developed for simulating Nitrogen fate, it is difficult to employ them in large scale due to the limited available field data. Hence, analytical methods, simple models, and LPMs are of interest in such cases. For instance, Saâdi et al. (2003) developed a simple model for a large-scale study of Nitrate contamination in the unsaturated zone for agricultural fields of the Mnasra with area of $500 \mathrm{~km}^{2}$. They developed a simple unsaturated zone model to describe Nitrogen dynamics in the field. They have estimated quantitatively seasonal Nitrate concentrations at different observation wells within a large area. All the aforementioned modeling tools are based on detailed geochemical input data of the porous media, which makes it difficult to apply in large-scale cases. For cases with insufficient data, LPMs are of great value. LPMs were introduced for the first time in 1950s and 1960s for interpretation of environmental radioisotope data in groundwater hydrology (Ling and El-Kadi 1998). In the recent decade, various analytical models have been developed using the first-order kinetic and linear isotherm equations to estimate pesticide contamination of groundwater. Ling and El-Kadi (1998) developed a LPM for Nitrogen transformation in the unsaturated zone for a soil-plant system. Since there are very few models developed for large urban areas with continuous discharge of wastewater that can explain temporal and spatial behavior of Ammonium and Nitrate in unsaturated zone, we have modified and applied a LPM based on Ling and El-Kadi (1998) in a geographic information system (GIS). This model needs less geochemical data compared with the abovementioned models. We have studied temporal and spatial contamination of Nitrate and Ammonium in unsaturated zone. Effect of depth on groundwater in retarding the discharged contamination in groundwater has been illustrated. In addition, the required time for reaching steady-state condition in unsaturated zone and the spatial distribution of contamination level has been studied.

\section{Geochemical processes}

Figure 1 shows major concepts of Nitrogen transformations associated with the soil-groundwater environment in cesspools or septic tanks. Bulk ratio of Nitrogen in wastewater at the cesspool is in form of urea, organic Nitrogen, and aqueous Ammonium. Urea can be hydrolyzed under anaerobic conditions, and Ammonium anion is produced (Wilhelm et al. 1994). Ammonium anion can be immobilized geochemically by adsorption to the soil. Nitrification process is fulfilled in two stages. At the first stage, in the presence of oxygen, Ammonia may be rapidly oxidized to Nitrite $\left(\mathrm{NO}_{2}{ }^{-}\right)$by the autotrophic Ammoniaoxidizing bacteria (Nitrosomonas). In the second stage, the autotrophic Nitrite-oxidizing bacteria oxidize Nitrite to Nitrate. Nitrite is a rather unstable Nitrogen species, which will generally be reduced or oxidized. However, Nitrate is quite soluble in water, and is not significantly adsorbed by clay-rich soils, since it is an anion. Usually, nitrification occurs mostly in the aerobic unsaturated zone, and it is thought generally that it is an oxic process. In some cases, Ammonia oxidizers are able to oxidize ammonia under anoxic conditions as explained by Wilhelm et al. (1994). Below the groundwater table, Nitrate can be reduced to Nitrogen gas. This process is called denitrification. It occurs primarily in anoxic conditions, and involves heterotrophic bacteria (Paracoccus, Pseudomonas). Additionally, in case of Nitrogen gas saturation in the groundwater, it tends to migrate out of the saturated zone. In spite of the fact that denitrification takes place in saturated zone under anoxic conditions, oxic denitrification has been also observed (Lee et al. 2006). In this case study, 
because of continuous discharge of wastewater for several decades, physical properties of this soil are different from a soil sample in an undisturbed area. In addition, due to the assumption of depth-averaged processes, nitrification and denitrification processes can be both considered in the same zone.

\section{Model description}

Concept of proposed LPM is shown in Fig. 2. Dispersive fluxes are neglected because of gravity effect and spatial setup of the model. Simplified equation of mass conservation for average concentration of contaminant in soil column is considered as follows:

$\partial(\theta c) / \partial t=-\partial(q c) / \partial z \pm($ Sink/Source $)$

where $\theta$ is the soil water content within depth $\left(\mathrm{cm}^{3} / \mathrm{cm}^{3}\right), q$ is the water flux (cm/day), $c$ is the solute concentration in solution $\left(\mathrm{mg} / \mathrm{cm}^{3}\right)$, and $z$ is the depth to groundwater $(\mathrm{cm})$.

By integrating Eq. 1 over depth to groundwater we can write:

$\int_{0}^{L} \partial(\theta c) / \partial t \mathrm{~d} z=-\int_{0}^{L} \partial(q c) / \partial z \pm \phi$

in which $\phi$ is a source/sink term. It can be assumed that depth $(L)$ is not dependent on time. This assumption is valid if groundwater table is not changing significantly. Based on this concept, average concentration in depth is of interest. Depth-averaged values of variables $\theta, c$, and $(\theta c)$ at a given time are defined as follows:

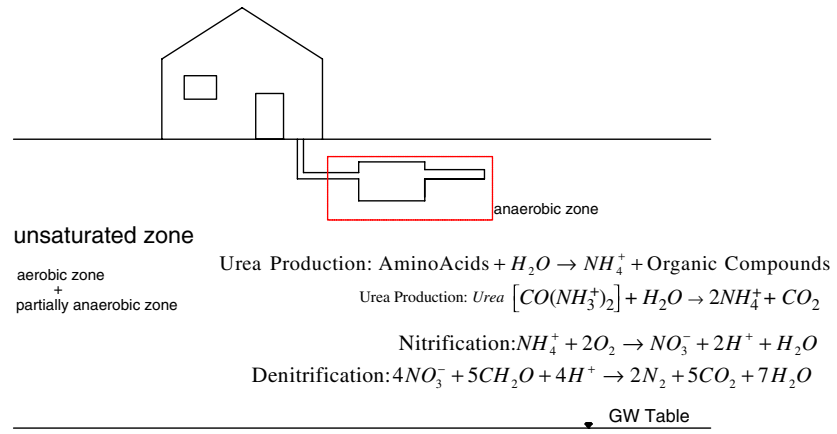

saturated zone

anaerobic zone

Fig. 1 Basic processes of nitrogen compounds in saturated and unsaturated zone

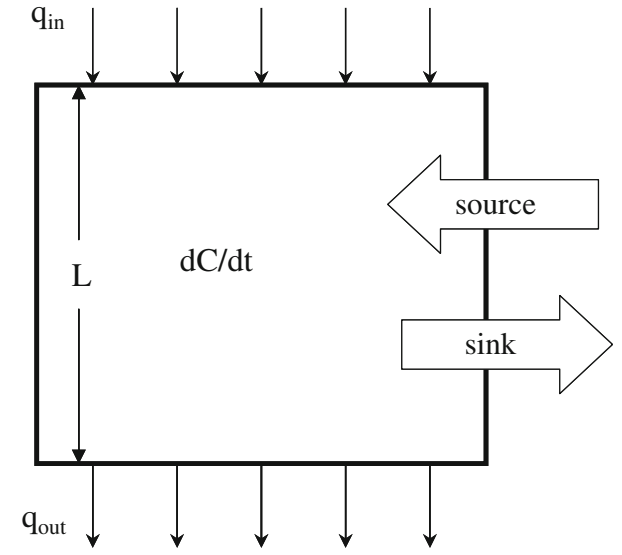

Fig. 2 Schematic of mass balance box

$\langle\theta\rangle=1 / L \int_{0}^{L} \theta(z, t) \mathrm{d} z$

$\langle c\rangle=1 / L \int_{0}^{L} c(z, t) \mathrm{d} z$

$\langle\theta c\rangle=1 / L \int_{0}^{L} \theta(z, t) c(z, t) \mathrm{d} z$

Rewriting Eq. 2 results:

$L\langle\partial(\theta c) / \partial t\rangle=c_{\text {in }} q_{\text {in }}-c_{\mathrm{t}} q_{\mathrm{t}} \pm \phi$

in which $c_{\mathrm{t}}$ is the concentration in solution below the depth of interest $\left(\mathrm{mg} / \mathrm{cm}^{3}\right), c_{\text {in }}$ is the dissolved concentration of contaminant applied to the top of depth of interest $\left(\mathrm{mg} / \mathrm{cm}^{3}\right), q_{\text {in }}$ is the inflow recharge per unit area $(\mathrm{cm} /$ day), $q_{\mathrm{t}}$ is the outflow from the depth of interest per unit area $(\mathrm{cm} /$ day $)$, and $\phi$ is the sink or source term over the depth.

To quantify the involved terms in such a large-scale problem in which temporal variation of variables $\theta$ and $c$ is not abrupt, an approximation to the left side of Eq. 6 is made, although mathematically it is not correct.

$L\langle\partial(\theta c) / \partial t\rangle \approx L\langle\theta\rangle \partial\langle c\rangle / \partial t+L\langle c\rangle \partial\langle\theta\rangle / \partial t$

Based on the mass balance principle, change of the average water content equals the inflows minus outflows from the soil column.

$L \partial\langle\theta\rangle / \partial t=\left.q\right|_{z=0}-\left.q\right|_{z=L}=P+I_{\mathrm{ww}}-q_{\mathrm{t}}$

where $P$ is the precipitation (cm/day) and $I_{\mathrm{ww}}$ is the wastewater inflow rate $(\mathrm{cm} /$ day $)$.

By inserting Eqs. 8 and 7 into Eq. 6, Eq. 9 will be obtained as follows: 


$$
\begin{aligned}
& (L\langle\theta\rangle) \mathrm{d}\langle c\rangle / \mathrm{d} t+\left(P+I_{\mathrm{ww}}\right)\langle c\rangle+\left(c_{\mathrm{t}}-\langle c\rangle\right) q_{\mathrm{t}} \\
& \quad=c_{\text {in }} q_{\text {in }} \pm \phi(t)
\end{aligned}
$$

It is assumed that the average concentration in the soil column is equal to the concentration at the bottom of soil column. Since urea is hydrolyzed to Ammonium rapidly in septic tanks and cesspools, the amount of urea in contrast to Ammonium is negligible. Considered processes in model include transformation of Ammonium to Nitrate (nitrification) with $k_{1}\left(\mathrm{day}^{-1}\right)$ rate, transformation of Nitrate to Nitrogen (denitrification) with $k_{2}\left(\mathrm{day}^{-1}\right)$ rate, soil adsorption, and volatilization of Ammonium to Ammoniac gas (Fig. 3). Finally, following set of equations are obtained:

$$
\begin{aligned}
& q_{\mathrm{o}}=P+I_{\mathrm{ww}} \\
&(L \bar{\theta}) \mathrm{d} A / \mathrm{d} t+q_{\mathrm{o}} A= q_{\mathrm{in}} A_{\mathrm{in}}-L\left(\rho_{\mathrm{b}} K_{\mathrm{dA}}+\varepsilon K_{\mathrm{H}}\right) \mathrm{d} A / \mathrm{d} t \\
&-k_{1}(L \bar{\theta} A) \\
&(L \bar{\theta}) \mathrm{d} N / \mathrm{d} t+q_{\mathrm{o}} N= q_{\mathrm{in}} N_{\mathrm{in}}+k_{1}(L \bar{\theta} A)-\left(L \rho_{\mathrm{b}} K_{\mathrm{dN}}\right) \mathrm{d} N / \mathrm{d} t \\
&-k_{2}(L \bar{\theta} N)
\end{aligned}
$$

where $K_{\mathrm{dA}}$ and $K_{\mathrm{dN}}$ are the distribution coefficients $\left(\mathrm{cm}^{3} / \mathrm{g}\right)$ of Ammonium and Nitrate, respectively. Attenuation rates for the transport of Ammonium and Nitrate are defined as $\lambda_{1}$ and $\lambda_{2}$, respectively, which are given as follows:

$\lambda_{1}=\left(1 / R_{\mathrm{FA}}\right)\left(k_{1}+q_{\text {in }} / L \bar{\theta}\right)$

$\lambda_{2}=\left(1 / R_{\mathrm{FN}}\right)\left(k_{2}+q_{\text {in }} / L \bar{\theta}\right)$

Solution of ordinary differential equations, Eqs. 11 and 12, will be as follows:

$A=\left(q_{\text {in }} A_{\text {in }} /\left(L R_{\mathrm{FA}} \bar{\theta} \lambda_{1}\right)\right)\left(1-\exp \left(-\lambda_{1} t\right)\right)+A_{\mathrm{o}} \exp \left(-\lambda_{1} t\right)$

$R_{\mathrm{FA}}=1+\rho_{\mathrm{b}} K_{\mathrm{dA}} / \bar{\theta}+\varepsilon K_{\mathrm{H}} / \bar{\theta}$

$R_{\mathrm{FN}}=1+\rho_{\mathrm{b}} K_{\mathrm{dN}} / \bar{\theta}$

where $R_{\mathrm{FA}}$ is the retardation factor of Ammonium (-), $A_{\mathrm{o}}$ is the initial concentration of Ammonium in soil $\left(\mathrm{mg} / \mathrm{cm}^{3}\right)$, and $R_{\mathrm{FN}}$ is the retardation factor of Nitrate (-).

Finally, solution of Eq. 12 will be as follows:

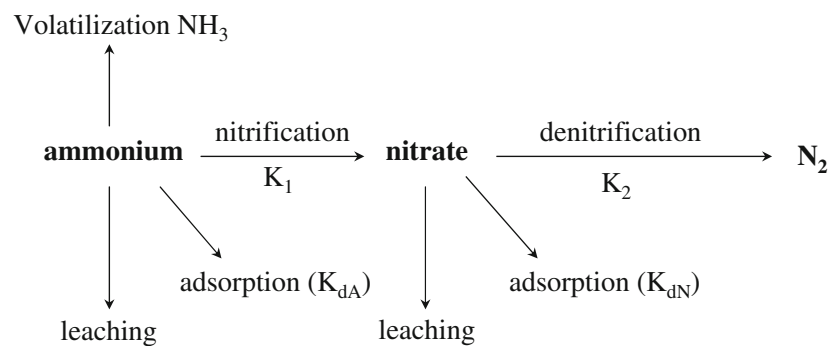

Fig. 3 Considered nitrogen transformations in LPM

$$
\begin{aligned}
N= & q_{\text {in }} /\left(L \bar{\theta} \lambda_{2} R_{\mathrm{FN}}\right)\left(N_{\text {in }}+k_{1} A_{\text {in }} /\left(R_{\mathrm{FA}} \lambda_{1}\right)\right) \\
& \left(1-\exp \left(-\lambda_{2} t\right)\right)+k_{1} /\left(R_{\mathrm{FN}}\left(\lambda_{2}-\lambda_{1}\right)\right) \\
& \left(A_{0}-q_{\text {in }} A_{\text {in }} /\left(L R_{\mathrm{FA}} \bar{\theta} \lambda_{1}\right)\right) \times\left(\exp \left(-\lambda_{1} t\right)-\exp \left(-\lambda_{2} t\right)\right) \\
& +N_{\mathrm{o}} \exp \left(-\lambda_{2} t\right)
\end{aligned}
$$

where $N_{\mathrm{o}}$ is the initial concentration of Nitrate in soil $\left(\mathrm{mg} / \mathrm{cm}^{3}\right), t$ is the time (day), and $\rho_{\mathrm{b}}$ is the soil bulk density $\left(\mathrm{g} / \mathrm{cm}^{3}\right)$.

\section{Description of the case study}

Tehran City has a population of more than 6.8 millions with a high dependency on the groundwater resources for drinking water (JICA and CEST 2000). About 35-55\% of water demand of Tehran is supplied by groundwater resource that is contaminated by individual traditional cesspools and septic tanks for many years (Mahmoudi 2001). The study area covers more than $500 \mathrm{~km}^{2}$ consisting of 20 municipal districts (Fig. 4). Constructing traditional cesspools and septic tanks is the conventional way for wastewater disposal, although in very few small areas there are wastewater disposal networks. Thus, wastewater is directly discharged into the subsurface. Because of the dense building construction, ground surface is almost covered by buildings, streets, and other impermeable surfaces. There are some limited park/recreational applications in the study area. Thus, major Nitrogen contamination sources can be considered as wastewater discharge, park and recreational spots, and air deposition.

Figure 5 shows spatial distribution of depth to groundwater as well as measurement points within the study area. Groundwater level has been measured in 87 points in three periods: March 2000, August 2000, and March 2001(Regional Water Authority of Tehran 2001). Observations show that groundwater level is not changing significantly during the measurement period. Since Tehran is located in southern domain of Elborz mountain chain, there is a moderate slope from north to south, and depth to groundwater table varies from 10 to $180 \mathrm{~m}$. Surface slope in southern parts is less than that in northern parts, and groundwater flow direction is from north to south. Mean annual precipitation varies between 250 and $350 \mathrm{~mm}$ decreasing towards south, which shows semiarid condition of the study area.

\section{LPM model setup}

Inflow data

As mentioned earlier, three main sources for Nitrogen in the study area are considered as follows: 
(a) Domestic wastewater: spatial distribution of wastewater quantity has been estimated using population projection. Japan International Cooperation Agency (JICA) and Centre for Earthquake and Environmental Studies of Tehran (CEST) (2000) have reported in details spatial distribution of demographic information in a GIS framework. We should note that Tehran population has increased dramatically during past two decades. Figure 6 shows trend of population increase in Tehran during the past century (Ohadi 2000; ISC 2008). Obviously rate of increase has decreased during recent years. According to TWWC (2000)

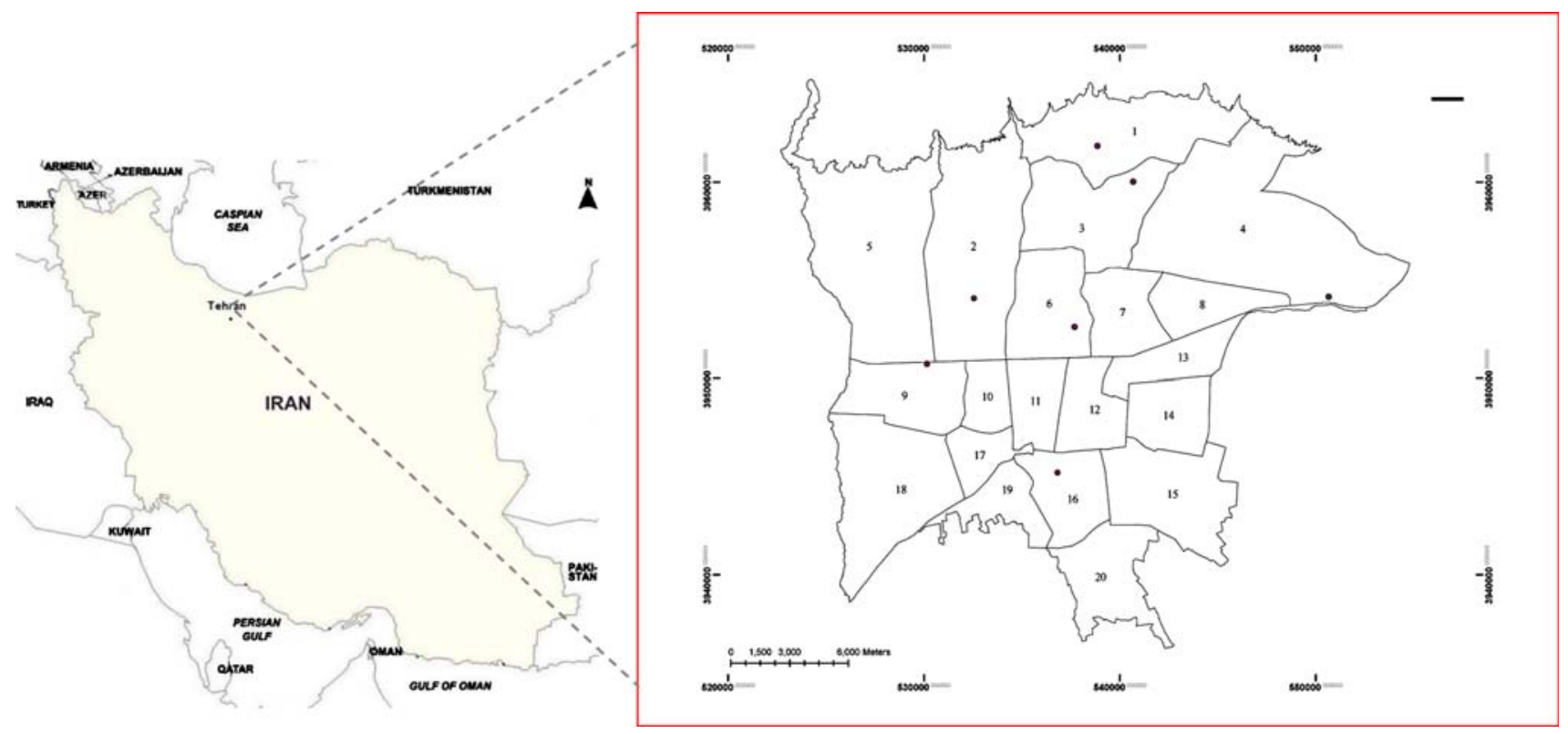

Fig. 4 Case study location and air quality control stations

Fig. 5 Spatial distribution of depth to groundwater (m) and location of measurement wells (2000-2001)

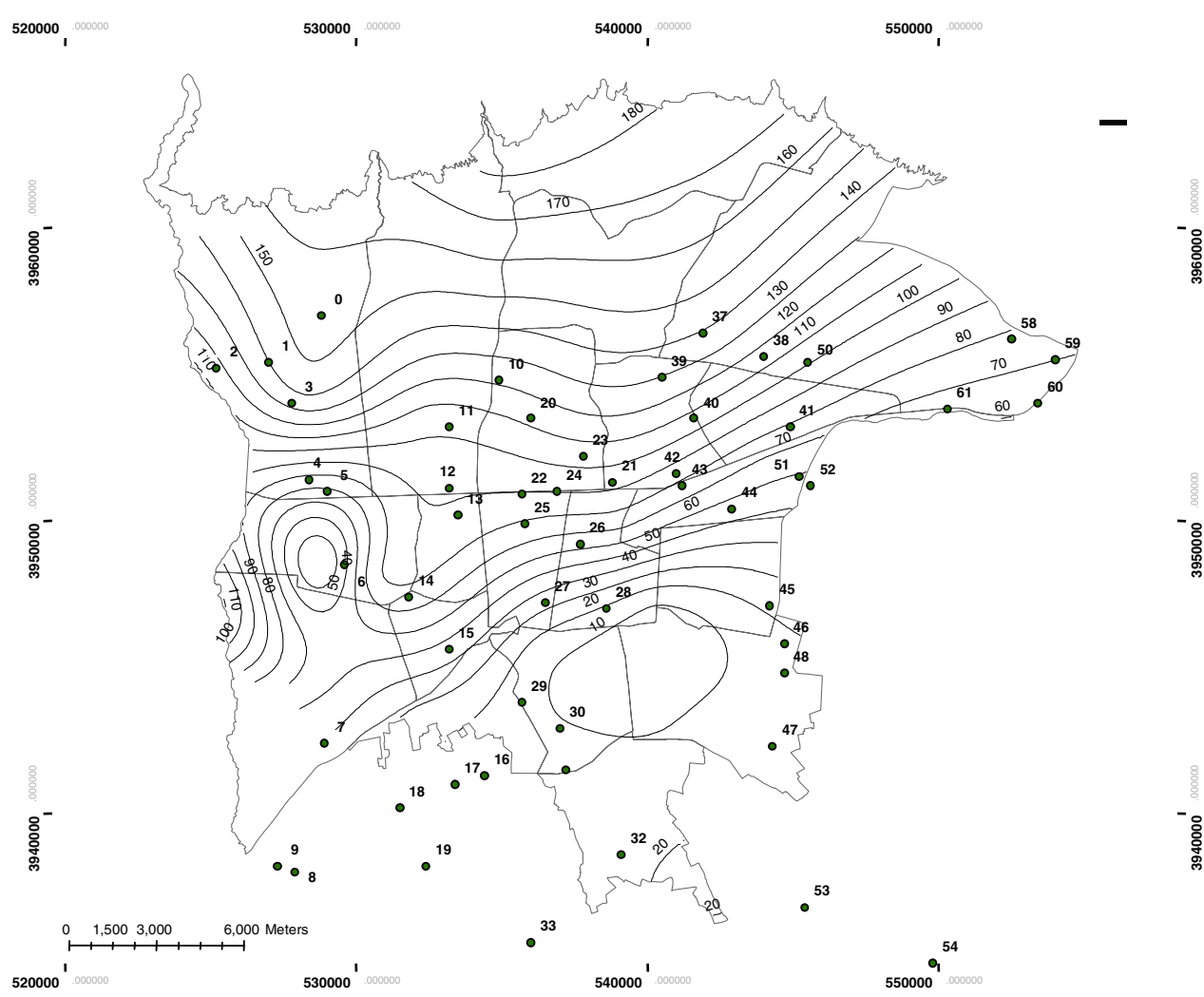




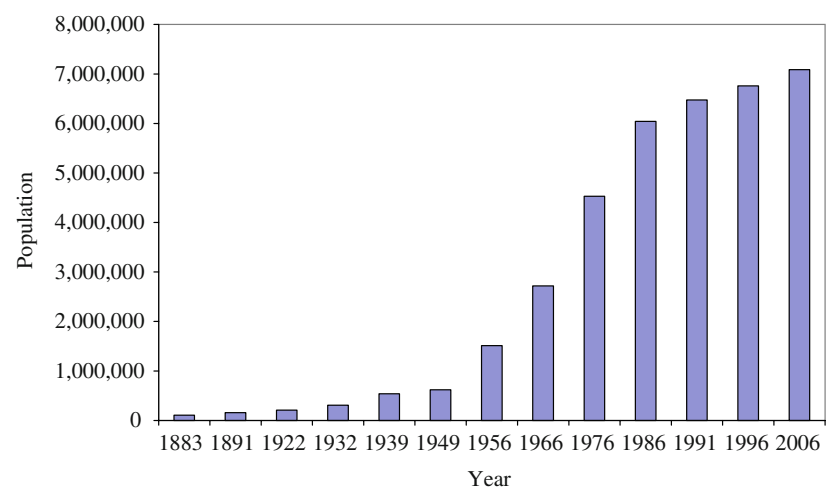

Fig. 6 Population increase in Tehran during the past century (Ohadi 2000; Iran Statistic Centre 2008)

wastewater discharge rate in Tehran is estimated about $162 \mathrm{~L} /$ day per capita. Annually average of wastewater quality is also presented in Table 1 . Based on the population projection in the study area and wastewater discharge rate, estimated annual Nitrogen loading is ranging from 270 to $305 \mathrm{~kg} \mathrm{~N} \mathrm{ha}^{-1}$ year $^{-1}$. Wakida and Lerner (2005) have reviewed various studies about non-agricultural sources of groundwater Nitrogen. Reported range of Nitrogen contamination from leaky sewers is about $3-123 \mathrm{~kg} \mathrm{~N} \mathrm{ha}^{-1}$ year $^{-1}$ in their review which is much smaller than loading level in this study.

(b) Atmospheric deposition: nitrogen compounds in atmosphere can be in oxidized or reduced forms. The oxidized compounds are generated by cars and industry. Reduced compounds are mainly released from agriculture and intensive feed stock rearing. To have a primary assessment of the importance of this source in contrast to the wastewater, wet deposition has been estimated roughly. Spatial distributions of atmospheric Nitrogen compounds and precipitation have been prepared based on seven air-quality control stations and four meteorological stations. Air Npollutant concentration have been measured in three stages with 6-month intervals in 2000 and 2001. Average air N-pollutant concentrations have been shown in Table 2. Estimated average wet deposition of Nitrogen is about $16.5 \mathrm{mg} \mathrm{N} \mathrm{m}^{-2}$ year $^{-1}$ (about 0.2 $\mathrm{kg} \mathrm{N} \mathrm{ha}{ }^{-1}$ year $^{-1}$ ). The highest reported value of atmospheric deposition is between 10 and $20 \mathrm{~kg} \mathrm{~N}$
Table 2 Average air N-pollutant concentration in Tehran (ppm) (2000-2001)

\begin{tabular}{llllll}
\hline Station & $\mathrm{X}(\mathrm{UTM})$ & $\mathrm{Y}(\mathrm{UTM})$ & $\mathrm{NOx}$ & $\mathrm{NO}_{2}$ & $\mathrm{NO}$ \\
\hline Tajrish & 538,853 & $3,961,851$ & 0.0960 & 0.0487 & 0.0473 \\
Villa & 537,687 & $3,952,603$ & 0.2931 & 0.0807 & 0.2123 \\
Sorkh-Hesar & 550,643 & $3,954,147$ & 0.0220 & 0.0163 & 0.0056 \\
Pardisan & 532,556 & $3,954,062$ & 0.1348 & 0.0728 & 0.0804 \\
Azadi & 530,156 & $3,950,726$ & 0.1910 & 0.0409 & 0.1500 \\
Gholhak & 540,668 & $3,960,011$ & 0.2465 & 0.0858 & 0.1565 \\
Bahman & 536,813 & $3,945,206$ & 0.2887 & 0.1705 & 0.1219 \\
\hline
\end{tabular}

$\mathrm{ha}^{-1}$ year $^{-1}$ in an industrial area covered with permeable surfaces under high range of precipitation (Wakida and Lerner 2005). Groffman et al. (2004) have measured Nitrogen loading for three successive years in an urban area. The highest amount of total Nitrogen loading is about $11.2 \mathrm{~kg} \mathrm{~N} \mathrm{ha}^{-1}$ year $^{-1}$. In both mentioned studies, run-off is discharged into the groundwater and contamination potential is much higher. Because of the physical features of the case study, which is covered mostly by impermeable surfaces as well as small amount of precipitation, amount of wet deposition compared to wastewater contamination potential can be neglected.

(c) Fertilizers: according to the standards, normally Nitrogen loading in park/recreational applications is about $200 \mathrm{~kg} \mathrm{~N} \mathrm{ha}^{-1}$ year $^{-1}$ (Lerner 2000). Based on the existing land-use map of the case study, covered surface by parks and grasslands has been estimated. Estimated total Nitrogen loading within the case study is estimated about 900 tons per year.

Comparing different aforementioned contamination sources, it is estimated that urban wastewater includes almost $95.5 \%$ of total nitrogen loading source. Parks/recreational applications and wet air deposition, which include $4.5 \%$ of total nitrogen loading source, are negligible compared to urban wastewater loading.

Outflow data

Concentration of Nitrogen compounds near to groundwater table is regarded as outflow. Groundwater quality has been

Table 1 Inflow wastewater quality at different wastewater treatment plants in Tehran (TWWC 2000) (mg/L of N)

\begin{tabular}{lccccrrr}
\hline Treatment plant & Jonoub & Ekbatan & Shoush & Saheb-gharanieh & Mahalati & Gheitarieh & Zargandeh \\
\hline Ammonium & 32.95 & 29.43 & 60.45 & 29.88 & 38.19 & 35.37 & 39.43 \\
Nitrate & 0.54 & 1.53 & 0.86 & 3.22 & 1.70 & 2.84 & 2.23 \\
Nitrite & 29.96 & 27.14 & 54.92 & 28.17 & 35.1195 & 32.99 & 36.44 \\
\hline
\end{tabular}


measured in 65 stations heterogeneously distributed in the study area. Regional Water Authority of Tehran (2001) has reported measurements of $\mathrm{NH}_{3}, \mathrm{NO}_{3}$, and $\mathrm{NO}_{2}$ in three periods in 2000 and 2001. Average concentration of these compounds over this period has been shown in Table 3 in Appendix.

Model parameters and variables

Because of the scarcity of geochemical data in the case study, model parameters have been determined based on literature, and they have been optimized based on available Nitrate concentration in groundwater for three successive periods.

Since the model structure is based on one-dimensional averaging in depth, the results are very sensitive to $k_{1}$ and $k_{2}$ values. In this case study, due to the physical specifications of the area such as continuous discharge of wastewater for several decades, range of variation of soil moisture is not wide and hence, soil-water content values are determined based on the data available from few geotechnical boreholes. In addition, MacQuarrie et al. (2001) has determined 0.4 for sandy aquifer under effect of septic tanks. Soil water content for gravel media is determined to be about 0.44 . In our study, average water content in soil media is about 0.40 . $\varepsilon$ and Henry coefficient are assumed to be equal to 0.15 and 2, respectively (Ling and El-Kadi,1998). Ammonium and Nitrate distribution coefficients are assumed equal to be 3.5
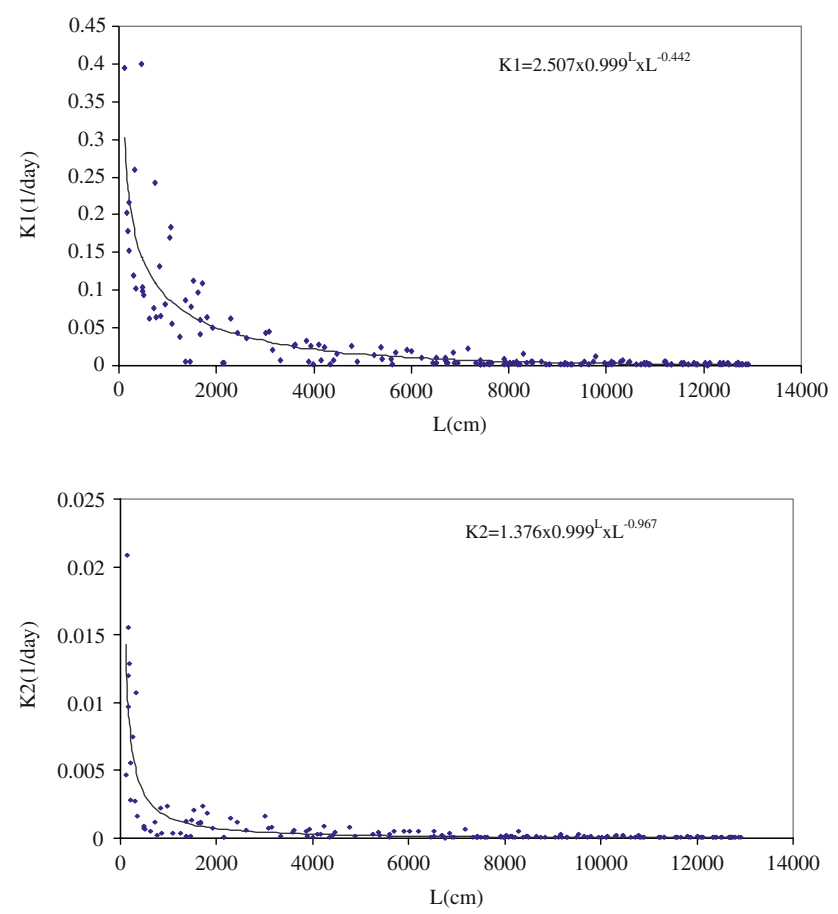

Fig. 7 Relationship between $k_{1}\left(\right.$ day $\left.^{-1}\right), k_{2}\left(\right.$ day $\left.^{-1}\right)$, and depth in LPM model and 0.001, respectively (Tillotson and Wagenet 1982). In this model, concentration is calculated as a mean value in depth that is considered fixed within depth. Hence, with increase of depth, error occurrence possibility for $k_{1}$ and $k_{2}$ increases. To solve this problem, a parametric model for these coefficients has been developed for different depths in which coefficients have been determined based on depth to groundwater. Figure 7 shows variation trend of coefficients in different depths. This method for determination of coefficients can solve partially the lack of field data.

\section{Results}

Spatial and temporal aspects of contamination

In this section, spatial and temporal behavior of Nitrate contamination is studied. In addition, steady-state condition of Nitrate in the study area is discussed. To get a better insight into the dynamics of Ammonium and Nitrate, typical breakthrough curves of these components are shown in Fig. 8. As mentioned earlier, constant flux has been assumed for boundary condition. In Fig. 8a, constant flux is applied for time less than 1,000 days, but in Fig. 8b, constant flux is applied for the whole simulation. Thus, a peak concentration in Fig. 8a and a steady-state condition in Fig. $8 \mathrm{~b}$ are expected. In Fig. 8a, it is clear that there is a delay time between peak concentration of Ammonium and Nitrate, due to the fact that Nitrate is produced after
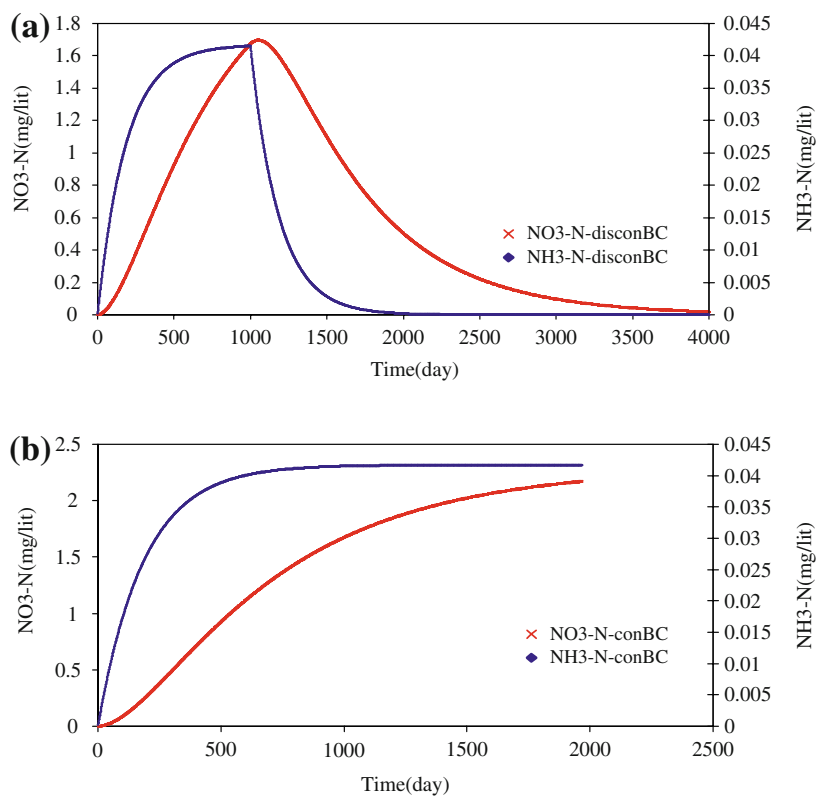

Fig. 8 Typical breakthrough curve of Nitrate and Ammonium in a soil column under (a) constant influx for $t<1,000$ days and under (b) constant influx for all $t$ 


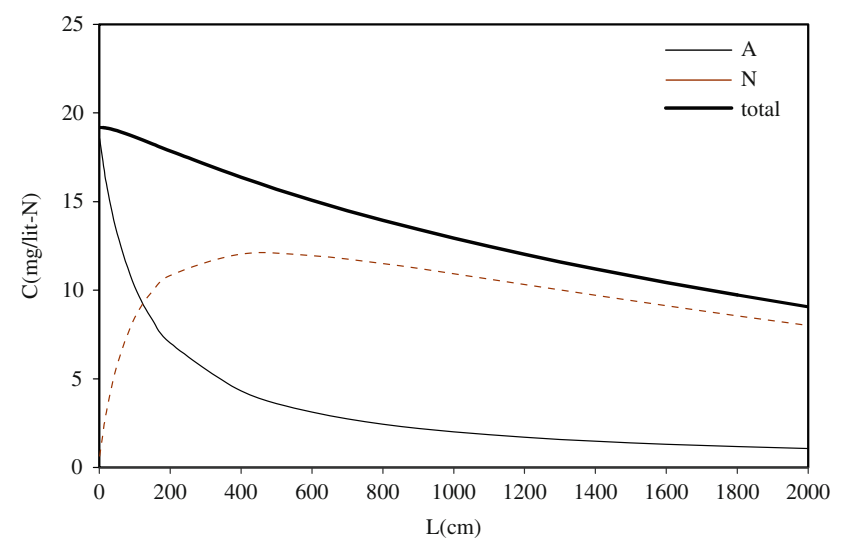

Fig. 9 Ammonium and Nitrate and total nitrogen concentration in different depths

Ammonium nitrification. Figure $8 \mathrm{~b}$ shows that Ammonium requires less time to reach the steady state, since it is a prime substance. Nitrate has much smaller absorption and transformation rates, and is a product of Ammonium transformation (nitrification). In addition, Fig. 9 shows concentration distributions of Nitrate and Ammonium and total nitrogen in depth. It shows that with increase of depth, total nitrogen discharged to the groundwater decreases due to transformation and adsorption. However, a peak concentration is observed for Nitrate, which is dependent on the sharp decrease of Ammonium. In depths lower than 5 $\mathrm{m}$, highest amount of Nitrate concentration is expected, which is in a good agreement with other studies (Foster et al. 1982; Antonakos and Lambrakis 2000). Since in the LPM concentrations are averaged in total depth of unsaturated zone, required time to reach the steady-state condition is highly dependent on the depth to groundwater and also on the boundary condition. We have assumed a constant depth to groundwater during our simulations. However, population distribution, which determines discharge to groundwater, has been normalized by population in 1996. Discharge has been updated during simulation with population in 1986, 1991, and 1996. Population after 2005 has been assumed to be constant. Based on these assumptions, Fig. 10 shows spatial distribution of the steady-state time in the study area. As it can be observed, depending on the depth to groundwater and local influx conditions, 2.5-946 years are required to reach the local steady-state condition. Southern parts of the study area that have smaller depth to groundwater compared to the northern parts can reach the steady-state conditions much faster. It is estimated that almost $50 \%$ of the study area will be in steady-state condition in 100 years considering existing demographic condition as the initial condition of the model. Because of the temporal evolution of concentration in the unsaturated zone, and also demographic development of Tehran, we compare model result in snapshot of 25 th year with measurement data. Figure 11 shows
Fig. 10 Spatial distribution of time to reach steady-state condition for nitrogen components

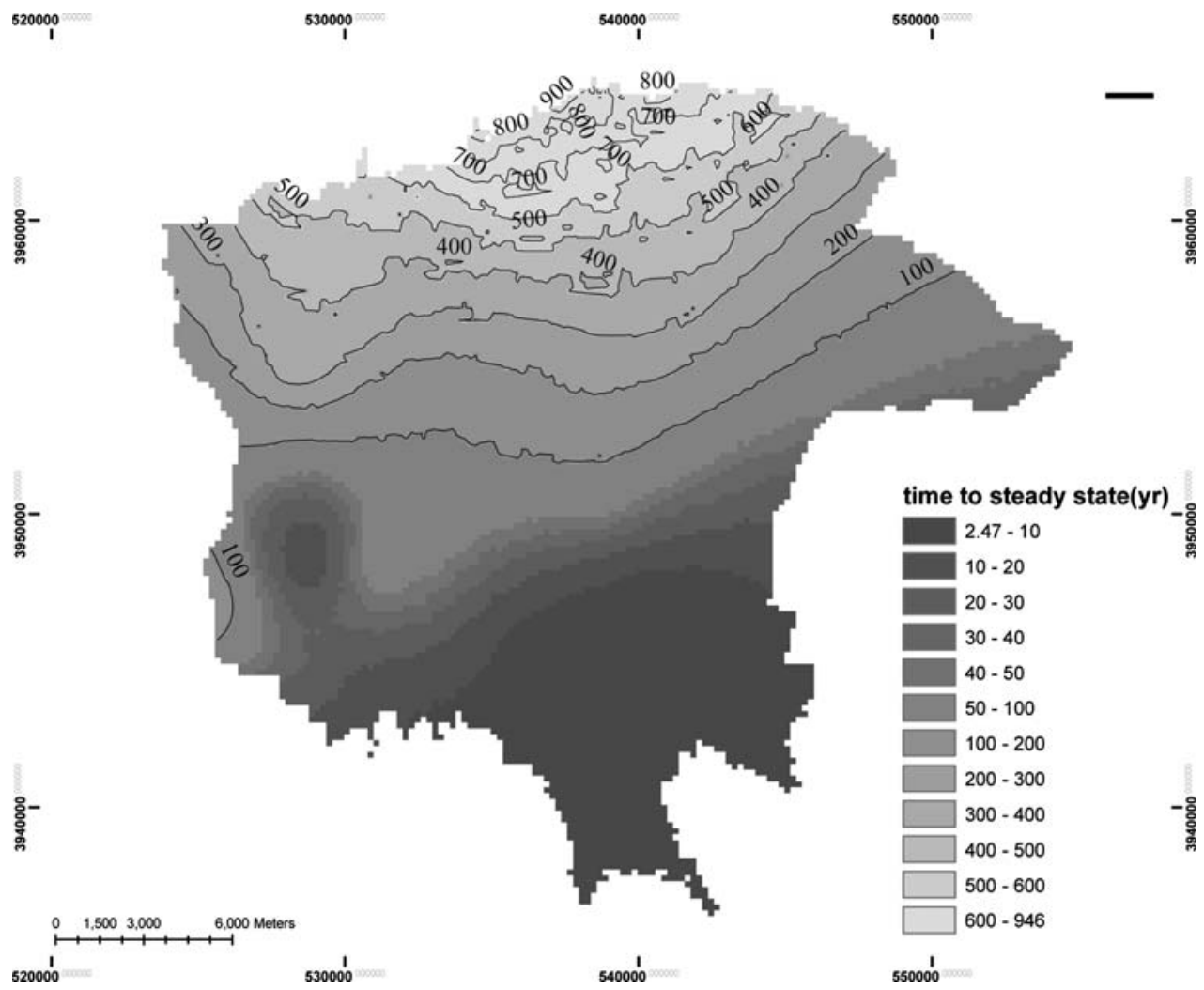


Fig. 11 Spatial distribution of Nitrate concentration $(\mathrm{mg} / \mathrm{L})$ based on measurements (2000-2001)

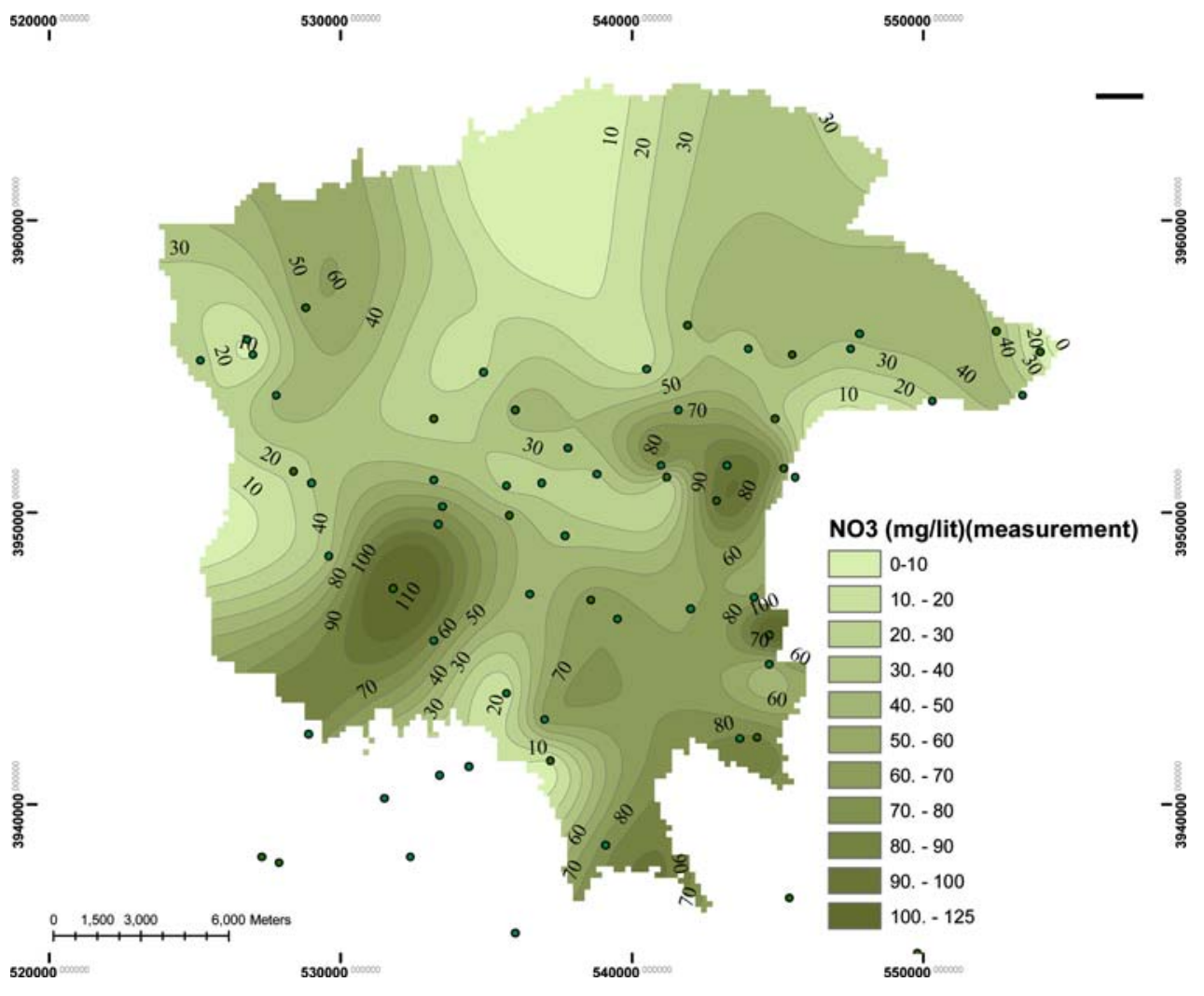

the spatial distribution of Nitrate concentration within 2000-2001. Maximum observed concentration of Nitrate in the measurement points is about $110 \mathrm{mg} / \mathrm{L}$. Figure $12 \mathrm{a}, \mathrm{b}$ shows concentration of Nitrate in 25th year and at steadystate condition, respectively. As it can be observed, contaminations in southern parts in both figures are similar, because they can reach the steady-state condition in less than 25 years. In addition, in northern parts, we have not observed high Nitrate contamination level in the measurements. However, if boundary conditions and wastewater disposal system do not change, northern parts will also suffer from high level of Nitrate contamination in future. It has been observed that subsurface contamination is directly controlled by wastewater discharge to groundwater.

\section{Model results analysis}

For comparing model results with field measurements, zonal analysis has been used. Thus, domain discritization has been applied by Vornoi diagram. Using Vornoi diagram, each measurement point will be representative for its region. Thus, higher density of data points will result in smaller region elements. Figure 13 shows the Vornoi map in the study area. As it can be seen in north or south-west of the study area, density of data points is much less than the central parts, which results in larger region (polygon) elements. We have compared averaged results of model (Fig. 12a) and measurement data (Fig. 11) per each (region) polygon element as shown in Fig. 14. Correlation coefficient between model results and measurement is about 0.73 , which is in an acceptable range. To identify in which zones higher disagreement between model and measurement is observed, relative error in each zone has been estimated. Relative error, Er, estimated for the simulated $\chi$ and measured value, $\langle\chi\rangle$, is defined as follows:

$\operatorname{Er}=\frac{|\chi-\langle\chi\rangle|}{\langle\chi\rangle}$

Figure 15 shows the relative error based on the Vornoi map. According to Fig. 15, in those region (polygon) elements, which are located in margins, larger relative error has been observed. Because of the lack of measurement points for groundwater quality outside the study area, we have to extrapolate the measurements. These extrapolated data are considered as the benchmark for comparing with model results. Thus, uncertainty increases not only due to the modeling procedure, but also due to bench mark definition for comparing with model results. Figure 15 shows that simulation results in majority of zones are in acceptable range with low relative errors (less than 20\%). Larger differences between the model results and the measurements are generally due to the uncertainty in field data extrapolation. However, the selected extrapolation strategy 
Fig. 12 Spatial distribution of

Nitrate concentration $(\mathrm{mg} / \mathrm{L})$ based on simulation (a) at year 25 and (b) at steady-state condition (a)

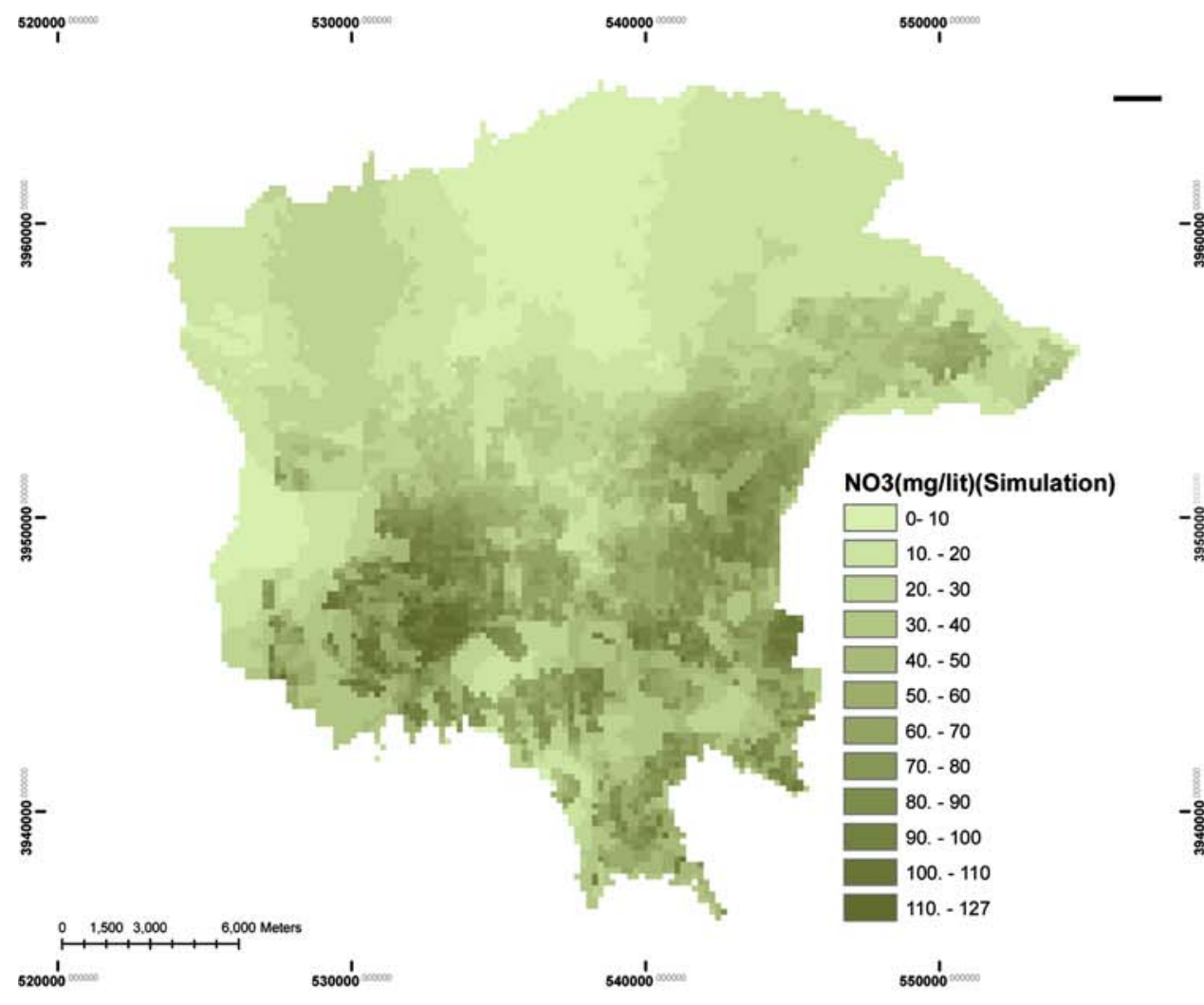

(b)

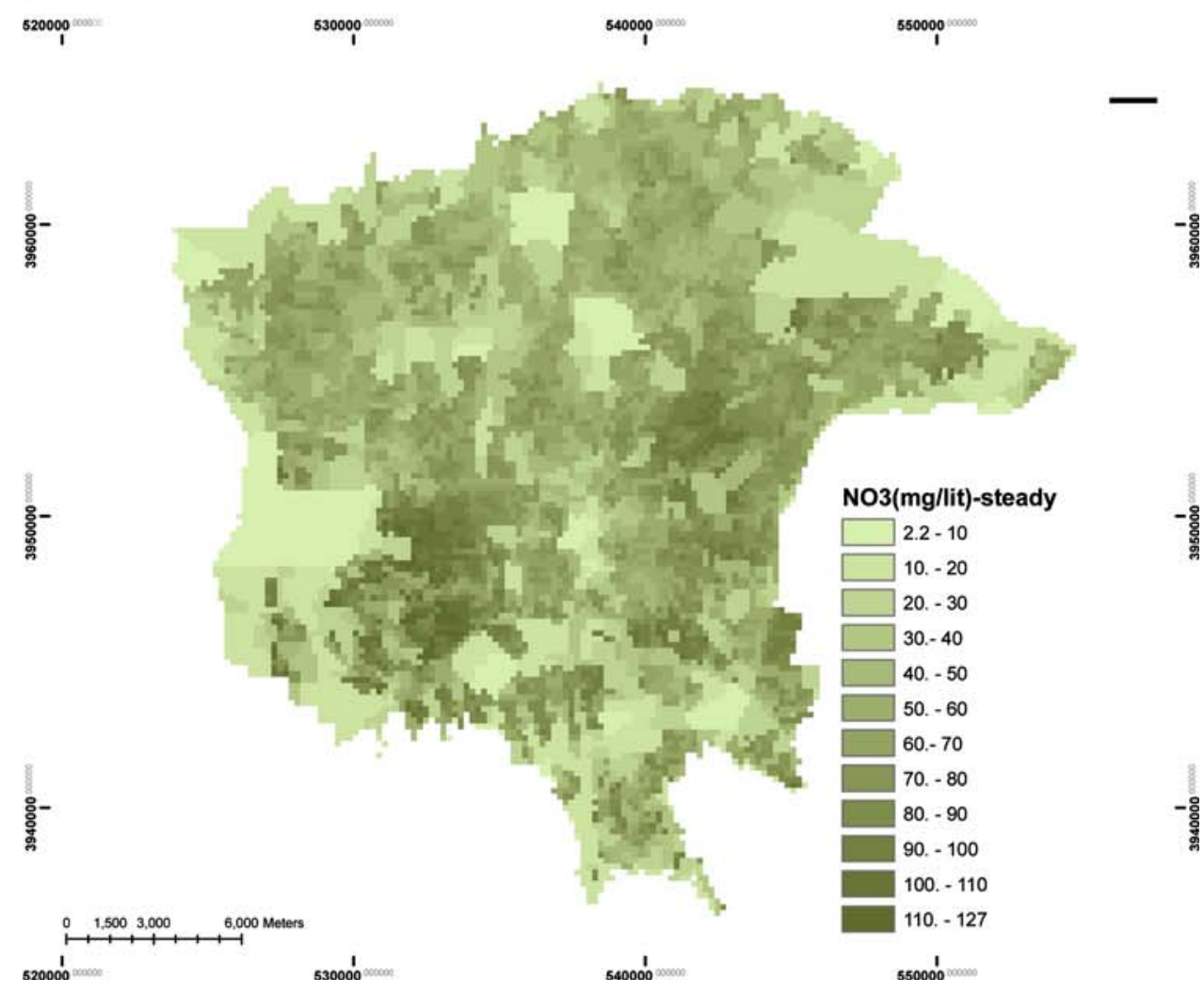


has been chosen so that minimum relative error between measurement and simulations occurs.

\section{Summary and remarks}

Large-scale modeling of Nitrate contamination in datalimited cases is a challenging task. In addition, involved processes in nitrogen fate in porous media are complicated. Furthermore, there are few studies related to large-scale modeling of Nitrate contamination due to the domestic wastewater. We have developed a LPM for modeling Nitrate and Ammonium fate in unsaturated zone neglecting dispersive fluxes to model nitrogen fate in unsaturated zone under the effect of continuous domestic wastewater discharge. We have applied this model in Large Tehran City $\left(>500 \mathrm{~km}^{2}\right)$ as a case study, which is highly contaminated by domestic wastewater discharge. Wastewater discharge, wet deposition, and parks/recreational applications have been assumed as Nitrogen sources. Using detailed demographic and landuse data in a GIS framework, total nitrogen loading from different sources has been assessed. More than $95 \%$ of nitrogen loading in Tehran City is discharged from domestic cesspools. LPM results show that in first few meters where nitrification occurs, highest Nitrate concentration level in depth can be observed. Simulations show that existing condition of Nitrate contamination in

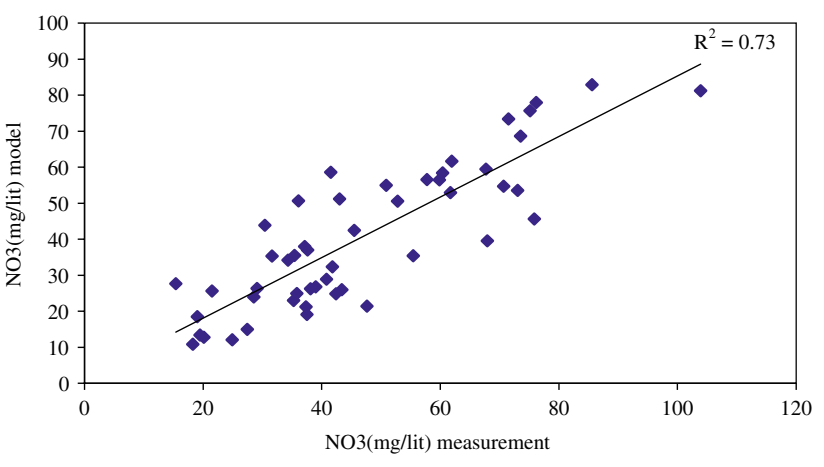

Fig. 14 Comparison between zonal mean of concentration resulted from simulation and field data for each Vornoi polygon

Tehran is in temporal condition. Since depth to groundwater controls the dynamics of N-pollution, it takes more time to reach the steady-state condition in deeper locations. In deeper depths, amount of contamination for both components decreases and required time to reach the steadystate condition for $\mathrm{N}$-contamination is nonlinearly proportional to the inverse of depth to groundwater. Spatial distribution of steady-state Nitrate concentration shows high risks in northern parts of study area in future. This result can be considered in groundwater quality management protocols in Tehran. Results analysis showed that in those locations in which more data points are available, smaller relative error has been observed. In spite of
Fig. 13 Vornoi diagram based on data points of groundwater quality measurements

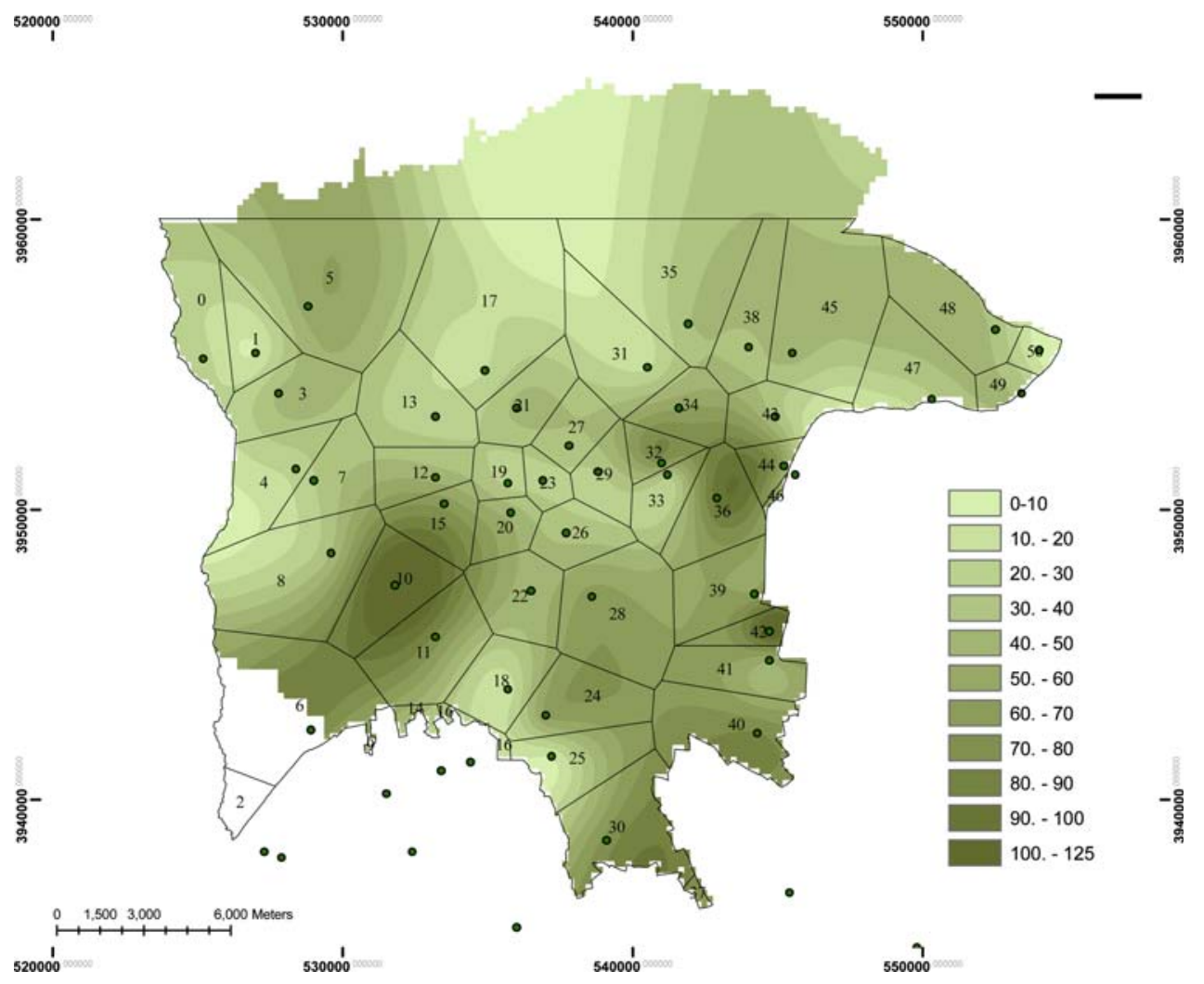


Fig. 15 Relative error of simulation result compared to measurements at each Vornoi polygon element

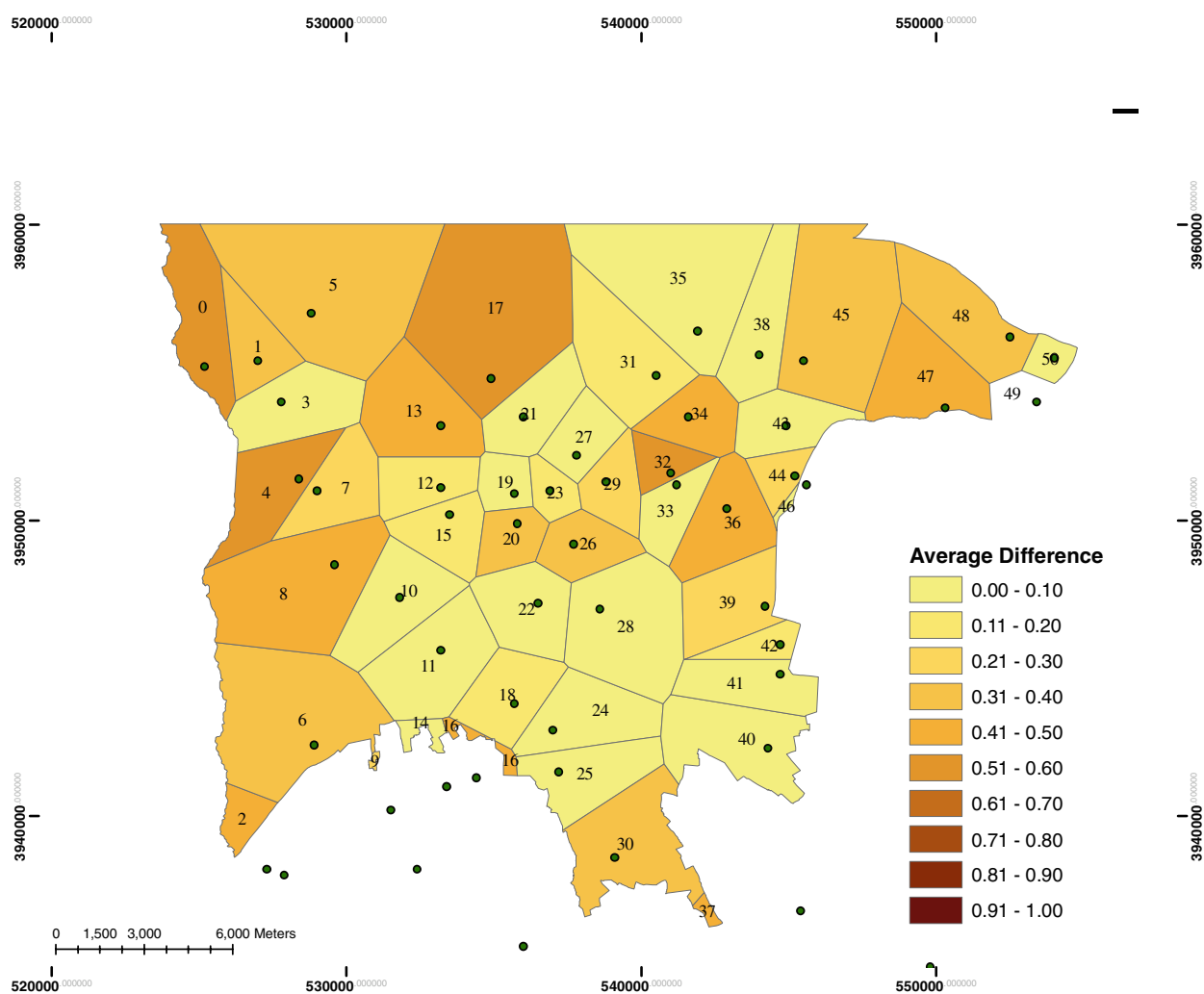

increased uncertainties due to the field data extrapolation, there is still acceptable agreement between LPM results and measurements with correlation coefficient of 0.73 .

Acknowledgments We would like to thank Ms. Z. Sattari for her help in analyzing wastewater input data and also anonymous reviewer for the valuable comments.

Open Access This article is distributed under the terms of the Creative Commons Attribution Noncommercial License which permits any noncommercial use, distribution, and reproduction in any medium, provided the original author(s) and source are credited.

\section{Appendix}

See Table 3.

Table 3 Average concentration of Nitrogen components in groundwater $(\mathrm{m} / \mathrm{L})(2000-2001)$

\begin{tabular}{llllrl}
\hline No. & $\mathrm{X}(\mathrm{UTM})$ & $\mathrm{Y}(\mathrm{UTM})$ & $\mathrm{NO}_{2}$ & \multicolumn{1}{l}{$\mathrm{NO}_{3}$} & $\mathrm{NH}_{3}$ \\
\hline 0 & 528,800 & $3,957,000$ & 0.028 & 55.100 & 0.346 \\
1 & 527,000 & $3,955,400$ & 0.004 & 9.800 & 0.244 \\
2 & 525,200 & $3,955,200$ & 0.006 & 23.000 & 0.257 \\
3 & 527,800 & $3,954,000$ & 0.004 & 41.620 & 0.294 \\
4 & 528,400 & $3,951,400$ & 0.002 & 23.600 & 0.306 \\
5 & 529,000 & $3,951,000$ & 0.013 & 29.800 & 0.266 \\
\hline
\end{tabular}

Table 3 continued

\begin{tabular}{llllrl}
\hline No. & $\mathrm{X}(\mathrm{UTM})$ & $\mathrm{Y}(\mathrm{UTM})$ & $\mathrm{NO}_{2}$ & \multicolumn{1}{l}{$\mathrm{NO}_{3}$} & $\mathrm{NH}_{3}$ \\
\hline 6 & 529,600 & $3,948,500$ & 0.014 & 39.900 & 0.210 \\
7 & 528,900 & $3,942,400$ & 0.005 & 80.300 & 0.450 \\
8 & 527,900 & $3,938,000$ & 0.009 & 2.900 & 0.427 \\
9 & 527,300 & $3,938,200$ & 0.014 & 25.700 & 0.534 \\
10 & 534,900 & $3,954,800$ & 0.008 & 19.600 & 0.665 \\
11 & 533,200 & $3,953,200$ & 0.001 & 25.400 & 0.382 \\
12 & 533,200 & $3,951,100$ & 0.009 & 46.100 & 0.500 \\
13 & 533,500 & $3,950,200$ & 0.002 & 66.400 & 0.260 \\
14 & 531,800 & $3,947,400$ & 0.005 & 124.800 & 0.300 \\
15 & 533,200 & $3,945,600$ & 0.007 & 77.000 & 0.633 \\
16 & 534,400 & $3,941,300$ & 0.016 & 22.100 & 0.435 \\
17 & 533,400 & $3,941,000$ & 0.006 & 16.900 & 0.270 \\
18 & 531,500 & $3,940,200$ & 0.040 & 9.100 & 0.311 \\
19 & 532,400 & $3,938,200$ & 0.002 & 36.400 & 0.353 \\
20 & 536,000 & $3,953,500$ & 0.010 & 42.900 & 0.680 \\
21 & 538,800 & $3,951,300$ & 0.007 & 29.500 & 0.330 \\
22 & 535,700 & $3,950,900$ & 0.031 & 27.400 & 0.487 \\
23 & 537,800 & $3,952,200$ & 0.006 & 36.700 & 0.360 \\
24 & 536,900 & $3,951,000$ & 0.004 & 27.600 & 0.473 \\
25 & 535,800 & $3,949,900$ & 0.015 & 46.100 & 0.360 \\
26 & 537,700 & $3,949,200$ & 0.005 & 36.400 & 0.540 \\
27 & 536,500 & $3,947,200$ & 0.085 & 45.200 & 0.420 \\
28 & 538,600 & $3,947,000$ & 0.080 & 64.200 & 0.550 \\
29 & 535,700 & $3,943,800$ & 0.006 & 14.500 & 0.260 \\
\hline & & & & &
\end{tabular}


Table 3 continued

\begin{tabular}{|c|c|c|c|c|c|}
\hline No. & X (UTM) & Y (UTM) & $\mathrm{NO}_{2}$ & $\mathrm{NO}_{3}$ & $\mathrm{NH}_{3}$ \\
\hline 30 & 537,000 & $3,942,900$ & 0.022 & 60.500 & 0.366 \\
\hline 31 & 537,200 & $3,941,500$ & 0.006 & 11.200 & 0.300 \\
\hline 32 & 539,100 & $3,938,600$ & 0.031 & 74.000 & 0.390 \\
\hline 33 & 536,000 & $3,935,600$ & 0.014 & 54.400 & 0.480 \\
\hline 34 & 536,400 & $3,933,400$ & 0.003 & 23.500 & 0.321 \\
\hline 35 & 535,300 & $3,930,100$ & 0.006 & 26.500 & 0.333 \\
\hline 36 & 538,800 & $3,928,300$ & 0.007 & 25.200 & 0.403 \\
\hline 37 & 541,900 & $3,956,400$ & 0.005 & 38.900 & 0.260 \\
\hline 38 & 544,000 & $3,955,600$ & 0.002 & 37.400 & 0.284 \\
\hline 39 & 540,500 & $3,954,900$ & 0.001 & 18.900 & 0.330 \\
\hline 40 & 541,600 & $3,953,500$ & 0.003 & 59.200 & 0.448 \\
\hline 41 & 544,900 & $3,953,200$ & 0.004 & 37.500 & 0.340 \\
\hline 42 & 541,000 & $3,951,600$ & 0.034 & 70.700 & 0.393 \\
\hline 43 & 541,200 & $3,951,200$ & 0.007 & 34.200 & 0.320 \\
\hline 44 & 542,900 & $3,950,400$ & 0.008 & 95.200 & 0.270 \\
\hline 45 & 544,200 & $3,947,100$ & 0.008 & 62.400 & 0.240 \\
\hline 46 & 544,700 & $3,945,800$ & 0.001 & 111.000 & 0.340 \\
\hline 47 & 544,300 & $3,942,300$ & 0.023 & 80.700 & 0.359 \\
\hline 48 & 544,700 & $3,944,800$ & 0.001 & 51.200 & 0.684 \\
\hline 49 & 543,750 & $3,934,600$ & 0.005 & 45.700 & 0.511 \\
\hline 50 & 545,500 & $3,955,400$ & 0.004 & 44.400 & 0.404 \\
\hline 51 & 545,200 & $3,951,500$ & 0.005 & 59.400 & 0.270 \\
\hline 52 & 545,600 & $3,951,200$ & 0.005 & 15.400 & 0.404 \\
\hline 53 & 545,400 & $3,936,800$ & 0.030 & 31.900 & 0.444 \\
\hline 54 & 549,800 & $3,934,900$ & 0.004 & 64.100 & 0.600 \\
\hline 55 & 549,800 & $3,934,400$ & 0.012 & 84.900 & 0.540 \\
\hline 56 & 548,500 & $3,929,000$ & 0.019 & 17.900 & 0.390 \\
\hline 57 & 547,100 & $3,928,000$ & 0.003 & 29.800 & 0.540 \\
\hline 58 & 552,500 & $3,956,200$ & 0.004 & 37.000 & 0.300 \\
\hline 59 & 554,000 & $3,955,500$ & 0.005 & 5.500 & 0.403 \\
\hline 60 & 553,400 & $3,954,000$ & 0.007 & 36.600 & 0.280 \\
\hline 61 & 550,300 & $3,953,800$ & 0.008 & 28.200 & 0.430 \\
\hline 62 & 553,200 & $3,934,000$ & 0.013 & 24.600 & 0.550 \\
\hline 63 & 550,950 & $3,926,700$ & 0.006 & 28.200 & 0.661 \\
\hline
\end{tabular}

\section{References}

Abu Maila Y, El-Nahal I, Al-Agha MR (2004) Seasonal variations and mechanisms of groundwater Nitrate pollution in the Gaza Strip. Environ Geol 47:84-90

Aller L, Bennet T, Lehr J, Petty R, Hackett G (1987) DRASTIC: a standardized system for evaluating ground water pollution potential using hydrogeologic settings (EPA-600/2-87-035). USEPA, Washington, DC

Antonakos A, Lambrakis N (2000) Hydrodynamic characteristics and Nitrate propagation in aquifer. Water Resour 34:3977-3986

Antonopoulos VZ, Wyseure GCL (1998) Modeling of water and Nitrogen dynamics on an undistributed soil and restored soil after open-cast mining. Agric Water Manage 37:21-40

Ataie-Ashtiani B, Hossaini SA (2005a) Error analysis of finite difference methods for two-dimensional advection-dispersionreaction equation. Adv Water Resour 28:793-806
Ataie-Ashtiani B, Hossaini SA (2005b) Numerical errors of explicit finite difference approximation for two-dimensional solute transport equation with linear sorption. Environ Modell Softw 20:817-826

Ataie-Ashtiani B, Lockington DA, Volker RE (1999) Truncation errors in finite difference models for solute transport equation with reaction term. J Contam Hydrol 35:409-428

D'Agostino V, Greene EA, Passarella G, Vurro M (1998) Spatial and temporal study of Nitrate concentration in groundwater by means of coregionalization. Environ Geol 36:3-4

DeSimone LA, Howes BL (1998) Nitrate transport and transformation in a shallow aquifer receiving wastewater discharge: a mass balance method. Water Resour Res 34:271-285

Foster SSD, Cripps AC, Smith-Carington A (1982) Nitrate leaching to groundwater. Philos Trans R Soc Lond B Biol Sci 296:477-489

Groffman PM, Law NL, Belt KT, Band LE, Fisher GT (2004) Nitrogen fluxes and retention in urban watershed ecosystems. Ecosystems 7:393-403

Hutson JL, Wagenet RJ (1991) Simulating Nitrogen dynamics in soils using a deterministic model. Soil Use Manag 7:74-78

Iran Statistic Centre (ISC) (2008) http://www.sci.org.ir/portal/faces/ public/sci/sci.gozide/sci.YearBook. Accessed 20 April 2008

Joekar-Niasar V (2003) Estimation of discharged amount of Nitrate to groundwater from septic tanks in Teheran, M.Sc. Thesis, Sharif University of Technology, Iran

Joekar-Niasar V, Ataie-Ashtiani B (2003) Nitrate contamination assessment from domestic septic tanks to water table. In: International Conference on Soil \& Groundwater Contamination \& clean-up in Arid Countries, Muscat, Oman, 20-23 January 2003

Japan International Cooperation Agency (JICA) and Centre for Earthquake and Environmental Studies of Tehran (CEST) (2000) The Study on seismic microzoning of the greater Tehran area in the Islamic Republic of Iran, Final Report: SSF J R 00-186

Ju XT, Kou CL, Zhang FS, Christie P (2006) Nitrogen balance and groundwater Nitrate contamination: comparison among three intensive cropping systems on the North China Plain. Environ Pollut 143:117-125

Kaluarachchi J, Parker JC (1998) Finite element model of Nitrogen species transformation and transport in the unsaturated zone. J Hydrol 109:249-274

Lagerstedt E, Jacks G, Sefe F (1994) Nitrate in groundwater and N circulation in eastern Botswana. Environ Geol 23:60-64

Lee MS, Lee KK, Hyuna Y, Clement TP, Hamil D (2006) Nitrogen transformation and transport modeling in groundwater aquifers. Ecol Modell 192:143-159

Lerner DN (2000) Guidelines for estimating urban loads of Nitrogen to groundwater, Groundwater Protection and Restoration Group, Department of Civil and Structural Engineering, University of Sheffield

Ling G, El-Kadi AI (1998) A lumped parameter model for Nitrogen transformation in the unsaturated zone. Water Resour Res 34:212-203

MacQuarrie KTB, Sudicky EA, Robertson WD (2001) Multicomponent simulation of wastewater-derived Nitrogen in shallow unconfined aquifers, I. Model formulation and performance. J Contam Hydrol 47:53-84

Mahmoudi S (2001) Thirsty city is not safe. In: Second international water and wastewater conference in Asian countries, Tehran

Nolan BT (2001) Relating Nitrogen sources and aquifer susceptibility to Nitrate in shallow ground water of the United States. Ground Water 39:290-300

Ohadi M (2000) Tehran, from the aspect of sociology. PhD Thesis, Freie Universitaet Berlin, Germany

Osborn NL, Eckenstein E, Koon KQ (1998) Vulnerability assessment of twelve major aquifers in Oklahoma. Oklahoma Water Resource Board, Technical Report 98-5 
Rupert MG (2001) Calibration of the DRASTIC ground water vulnerability mapping method. Ground Water 39:625-630

Saâdi Z, Maslouhi A, Abdellatif M (2003) Modeling Nitrogen dynamics in unsaturated soils for evaluating Nitrate contamination of the Mnasra groundwater. Adv Environ Res 7:803-823

Schilling KE, Wolter CF (2007) A GIS-based groundwater travel time model to evaluate stream Nitrate concentration reductions from land use change. Environ Geol 53:433-443. doi:10.1007/ s00254-007-0659-0

Spalding RF, Exner ME (1993) Occurrence of Nitrate in groundwater-a review. J Environ Qual 22:392-402

Regional Water Authority of Tehran (RWAT) (2001) Quality and quantity of Tehran groundwater, Report TW-29-G-2000

Tehran Water and Wastewater Company (TWWC) (2000) Detailed report on water and wastewater statistic of Tehran, TWWC-10$313-2000$
Tesoriero AJ, Voss FD (1997) Predicting of elevated Nitrate concentration in the Puget Sound Basin: implication for susceptibility and vulnerability. Ground Water 35:1029-1040

Tillotson WR, Wagenet RJ (1982) Simulation of fertilizer Nitrogen under cropped situation. Soil Sci 133:133-143

Wakida FT, Lerner DN (2005) Non-agricultural sources of groundwater Nitrate: a review and case study. Water Res 39:3-16

World Health Organization (1996) Guidelines for drinking-water quality, 2nd edn. Health criteria and other supporting information. WHO, Geneva

Wilhelm SR, Schiff SL, Cherry JA (1994) Biogeochemical of domestic waste water in septic system: 1. Conceptual model. Ground Water 32:915-905 